\title{
High value and cheap musculoskeletal health care interventions: lessons for low- and middle-income countries
}

\author{
Monu Tamang ${ }^{1^{*}}$ (D) and Kuenzang Wangdi ${ }^{2,3}$ (B)
}

To the Editor,

The Global Burden of Disease Study 2019 reported low back pain and other musculoskeletal disorders constitute the top ten cause of disability-adjusted life-year and are common from teenage years into old age [1]. The number of people experiencing musculoskeletal conditions in the coming decades will increase in low- and middle-income countries (LMICs) [2]. In addition to the likelihood of risk factors such as increased life expectancy and obesity associated with musculoskeletal conditions in highincome countries becoming more common in LMICs, the burden of musculoskeletal conditions will increase as a result of physically demanding agrarian work, and arduous portering due to poor access to modern transportation system [2].

In the past decades, the largest increase in disability due to low back pain occurred in LMICs, including Asia, Africa, and the Middle East region [2], where resourceconstrained health and social systems are stressed by other burdens including infectious diseases, child and maternal health, and non-communicable diseases. The Lancet series on low back pain reported healthcare professionals in LMICs are providing wrong care for low back pain [3], resulting not only in burdens to individuals, communities, and health care systems but also contravening the 2010 Declaration of Montreal, which recognises pain relief as fundamental human right.

\footnotetext{
*Correspondence: monutamang.pt@gmail.com

${ }^{1}$ Physiotherapy Unit, Central Regional Referral Hospital, Gelegphu, Bhutan

Full list of author information is available at the end of the article
}

Therefore, LMICs should develop innovative health policies to address this concern with fiscally cheaper but high value care. In this paper, the musculoskeletal conditions refer to the chronic, non-traumatic musculoskeletal pain disorders.

\section{Judicious usage of radiological imaging}

Injudicious radiological imaging is expensive while it may not yield any clinical benefit. For example, an MRI scan would cost up to one third of average monthly household income in Nepal [4]. Likewise, MRI scanning on patients with early stage of non-specific low back pain is likely to encourage surgeries, consequently incurring greater costs of care, increased usage of prescribed opioids, and increased intensity of pain during follow-up sessions [5]. The MRI and ultrasound tend to establish causal relationship between structural abnormalities and symptoms, leading to medicalising normality and necessitating unwarranted interventions on normal age-related changes that are unrelated to the symptoms [6].

Conversely, a review of high-quality clinical guidelines recommends imaging only if (i) serious pathologies such as infection, malignancy, fracture, inflammatory cause of pain, progressive neurological deficits including cauda equina syndrome, and serious pathology mimicking musculoskeletal pain such as aortic aneurysm are suspected; (ii) unsatisfactory response to exhaustive and evidencebased conservative management and unexplained progressions of signs and symptoms are observed; and (iii) imaging will likely change the management [7]. 


\section{Surgery-an expensive placebo}

Advancement in assessment and management of musculoskeletal conditions such as fracture have improved patient care [6]. However, many surgical procedures in musculoskeletal healthcare are no better than skin incisions and sham surgery as far as pain is concerned [8]. Such surgeries include excision of degenerative portion of extensor carpi radialis brevis in lateral elbow tendinopathy and arthoscopic lavage and debridement of osteophytes in knee osteoarthritis. These surgeries are not only expensive for healthcare systems and patients but are also associated with increased clinical risks and often do not offer additional clinical benefits [6].

\section{Opioids - no more a panacea for all ills}

The opioid epidemic in some developed countries is an example of how modern medicines are related to serious side effects. In the USA, since 1999, almost half a million people died from opioids overdose, with more than 50,000 deaths in 2019 alone. Likewise, the prolonged use of non-steroidal anti-inflammatory drugs is associated with about 100,000 hospitalisation and 17,000 associated deaths annually in the USA [9].

Opioids could be helpful for palliative care, cancer pain, and acute post-surgical pain; however, its use in persistent pain is associated with hyperalgesia, dependence, death, and poor functional outcomes. Non-steroidal anti-inflammatory drugs such as paracetamol are ineffective for low back pain and provide only shortterm relief in osteoarthritis [10]. Additionally, clinical practice guidelines consistently recommend non-pharmacological treatments such as physiotherapy and psychological therapies for persistent musculoskeletal pain disorders.

\section{Way forward}

Non-surgical and non-pharmacological management in non-traumatic musculoskeletal conditions are relatively cheap, safe, and effective. Such management includes patient-centered education, physical activity and exercise, social activities, healthy sleep habits, body weight management, remaining in the employment, and psychological therapies. Graded activities and exercises are as effective as surgery for shoulder pain, knee pain, and ankle sprains [6]. Therefore, it is sensible for LMICs to prioritize equally effective but cheaper management options over traditional surgical and pharmacological treatments.

\section{Abbreviations}

LMICs: Low- and middle-income countries; MRI: Magnetic resonance imaging.

\section{Acknowledgements}

Not applicable.

Authors' contributions

MT and KW were involved in conception. MT wrote the first draft. MT and $\mathrm{KW}$ revised the article and approved the final manuscript.

\section{Authors' information}

Not applicable.

Funding

No funding available.

Availability of data and materials

Not available.

\section{Declarations}

Ethics approval and consent to participate

Not applicable.

Consent for publication

Not applicable.

\section{Competing interests}

The authors declare that they have no competing interests.

\section{Author details}

${ }^{1}$ Physiotherapy Unit, Central Regional Referral Hospital, Gelegphu, Bhutan. ${ }^{2}$ Department of Orthopaedics, Jigme Dorji Wangchuck National Referral Hospital, Thimphu, Bhutan. ${ }^{3}$ Faculty of Post Graduate Medicine, Khesar Gyalpo University of Medical Sciences of Bhutan, Thimphu, Bhutan.

Received: 2 June 2021 Accepted: 5 December 2021

Published online: 16 February 2022

\section{References}

1. Abbafati C, Abbas KM, Abbasi-Kangevari M, Abd-Allah F, Abdelalim A, Abdollahi M, et al. Global burden of 369 diseases and injuries in 204 countries and territories, 1990-2019: a systematic analysis for the Global Burden of Disease Study 2019. Lancet. 2020:396(10258):1204-22.

2. Hoy DG, Smith E, Cross M, Sanchez-Riera L, Blyth FM, Buchbinder R, et al. Reflecting on the global burden of musculoskeletal conditions: lessons learnt from the global burden of disease 2010 study and the next steps forward. Ann Rheum Dis. 2015;74(1):4-7.

3. Foster NE, Anema JR, Cherkin D, Chou R, Cohen SP, Gross DP, et al. Prevention and treatment of low back pain: evidence, challenges, and promising directions. Lancet. 2018;391(10137):2368-83.

4. Sharma S, Traeger AC, Mishra SR, Sharma S, Maher CG. Delivering the right care to people with low back pain in low- and middle-income countries: the case of Nepal. J Glob Health. 2019;9(1):9-11.

5. Jacobs JC, Jarvik JG, Chou R, Boothroyd D, Lo J, Nevedal A, et al. Observational study of the downstream consequences of inappropriate MRI of the lumbar spine. J Gen Intern Med. 2020;35(12):3605-12.

6. Lewis JS, Cook CE, Hoffmann TC, O'Sullivan P. The elephant in the room: too much medicine in musculoskeletal practice. J Orthop Sports Phys Ther. 2019;50(1):1-4.

7. Lin I, Wiles L, Waller R, Goucke R, Nagree Y, Gibberd M, et al. What does best practice care for musculoskeletal pain look like? Eleven consistent recommendations from high-quality clinical practice guidelines: systematic review. Br J Sports Med. 2020;54(2):79-86.

8. Louw A, Diener I, Fernández-de-Las-Peñas C, Puentedura EJ. Sham surgery in orthopedics: a systematic review of the literature. Pain Med. 2017;18(4):736-50.

9. Rane MA, Foster JG, Wood SK, Hebert PR, Hennekens CH. Benefits and risks of nonsteroidal anti-inflammatory drugs: methodologic 
limitations lead to clinical uncertainties. Ther Innov Regul Sci.

2019:53(4):502-5.

10. Machado GC, Maher CG, Ferreira PH, Pinheiro MB, Lin CWC, Day RO, et al.

Efficacy and safety of paracetamol for spinal pain and osteoarthritis:

systematic review and meta-analysis of randomised placebo controlled trials. BMJ. 2015;350:1-13.

\section{Publisher's Note}

Springer Nature remains neutral with regard to jurisdictional claims in pub-

lished maps and institutional affiliations.

\section{Submit your manuscript to a SpringerOpen ${ }^{\circ}$ journal and benefit from:}

- Convenient online submission

- Rigorous peer review

- Open access: articles freely available online

- High visibility within the field

- Retaining the copyright to your article

Submit your next manuscript at $\boldsymbol{\nabla}$ springeropen.com 